\title{
Disrespect and abuse during facility-based childbirth in southern Mozambique: a cross-sectional study
}

\author{
Anna Galle ${ }^{1 *}$, Helma Manaharlal ${ }^{2}$, Emidio Cumbane ${ }^{2}$, Joelma Picardo², Sally Griffin², Nafissa Osman²,3, \\ Kristien Roelens ${ }^{1}$ and Olivier Degomme ${ }^{1}$
}

\begin{abstract}
Background: Evidence suggests that many women experience mistreatment during childbirth in health facilities across the world, but the magnitude of the problem is unknown. The occurrence of disrespect and abuse (D\&A) in maternity care services affects the overall quality of care and may undermine women's trust in the health system. Studies about the occurrence of disrespect and abuse in Mozambican health facilities are scarce. The aim of this study was to explore the experience of women giving birth in hospital in different settings in Maputo City and Province, Mozambique.
\end{abstract}

Methods: A cross sectional descriptive survey was conducted between April and June 2018 in the Central Hospital of Maputo (HCM) and district hospitals of Manhiça and Marracuene, Maputo Province, Mozambique. Five hundred seventy-two exit interviews were conducted with women leaving the hospital after delivery. The questionnaire consisted of the following components: socio-demographic characteristics, the occurrence of disrespect and abuse, male involvement during labor and childbirth and intrapartum family planning counselling and provision.

Results: Prevalence of disrespect and abuse ranged from $24 \%$ in the central hospital to $80 \%$ in the district hospitals. The main types of D\&A reported were lack of confidentiality/privacy, being left alone, being shouted at/scolded, and being given a treatment without permission. While very few women's partners attended the births, the majority of women (73-80\%) were in favor of involving their partner as a birth companion. Intrapartum counseling of family planning was very low (9-17\%).

Conclusion: The occurrence of disrespect and abuse was much higher in the district hospitals compared to the central hospital, emphasizing the high need for interventions outside Maputo City. Allowing male partners as birth companions should be explored further, as women seem in favor of involving their partners. Investing in intrapartum counselling for family planning is currently a missed opportunity for improving the uptake of contraception in the country.

Keywords: Disrespect and abuse, Mozambique, Quality of care, Maternal health, Family planning, Male involvement

\section{Introduction}

Maternal mortality refers to deaths caused by complications from pregnancy or delivery. From 1990 to 2015, during the Millennium Development Goals (MDGs) era, the global maternal mortality ratio declined by $44 \%-$ from 385 deaths to 216 deaths per 100,000 live births,

\footnotetext{
* Correspondence: anna.galle@ugent.be

${ }^{1}$ International Centre for Reproductive Health, Department of Public Health and Primary Care, Ghent University, Corneel Heymanslaan 10, entrance 75, UZP 114, 9000 Ghent, Belgium

Full list of author information is available at the end of the article
}

based on UN inter-agency estimates. Despite the fact that every region has advanced, the maternal mortality ratio is still very high in sub-Saharan Africa compared to the rest of the world [1]. Maternal mortality reduction remains a priority under in the new Sustainable Development Goals (SDGs). By 2030, the global community wants to reduce the global maternal mortality ratio (MMR) to fewer than 70 maternal deaths per 100,000 live births.

Global efforts during the MDGs era have largely focused on increasing antenatal care (ANC) coverage and 
facility-based childbirth as a key mechanism to reduce maternal mortality [2]. These efforts met with some success. There was much less emphasis on quality of care, although individual studies suggest that poor quality is limiting health gains [3, 4]. Improving quality of care, along with women's experiences of care, has been highlighted as a key strategy to further reduce preventable maternal mortality and morbidity and achieve the healthrelated SDG targets by the World Health Organization (WHO) [5]. In 2016, WHO published new guidelines for improving quality of care for mothers and newborns in health facilities, which included an increased focus on respect and preservation of dignity. Experience of care is as important as clinical care provision in achieving the desired person-centred outcomes in the WHO framework for improving quality of care for pregnant women during childbirth [5]. Recent evidence suggests that many women experience mistreatment and are abandoned during childbirth in health facilities across the world, but the magnitude of the problem is unknown [6-10]. An often cited framework for describing interpersonal aspects of care during labor and delivery are the seven domains of disrespect and abuse (D\&A) defined in Bowser and Hill's landscape evidence review, published in 2010: physical abuse; non-consented care; non-confidential care; non-dignified care; discrimination; abandonment of care; and detention in facilities [11]. Afterwards The White Ribbon Alliance spread the Respectful Maternity Care Charter: The Universal Rights of Childbearing Women, a statement grounded in the Universal Declaration of Human Rights [12].

The mistreatment of women during childbirth often occurs at the level of the interaction between women and healthcare providers but deficiencies in the health care system (e.g. lack of adequate personal and poor infrastructure) also contribute to its occurrence [13-15]. The occurrence of disrespect and abuse in maternity care services may undermine women's trust in the health system and deter them from seeking facility-based care for delivery [16]. Disrespect and abuse during childbirth is more and more being recognized as an indicator of poor quality of care and cited as a key barrier in achieving better maternal health outcomes [17].

Mozambique, with a maternal mortality ratio of 489 maternal deaths per 100000 livebirths in 2015 and only $54 \%$ of births attended by a skilled birth attendant, is one of the priority countries for improving maternal health [18]. Several actions have been taken and progress is ongoing but slow. Recognising the importance of quality of care, since 2007 the MoH (Ministry of Health) of Mozambique has made humanization and patient friendly care during ANC and delivery one of its priorities [11]. Over time, the culture of promoting Respectful Maternity Care (RMC) has become more widespread in Mozambique and the MoH has transformed a selection of maternity wards into centers of quality and humanized Maternal and Newborn Health $(\mathrm{MNH})$ care provision under the "Iniciativa Maternidade Modelo" (Model Maternity Initiative). Respectful maternity care is one of the essential packages of the model and includes respect for beliefs, traditions, and culture; the right to information and privacy; choice of a companion; freedom of movement and position; skin-toskin contact and early breastfeeding; appropriate use of technology and effective lifesaving interventions; and prevention of violence and disrespectful care [11]. By 2017 the initiative was implemented in all hospitals (central, provincial and district) within the country and almost half of the health centres [unpublished report JHPiego \& $\mathrm{MoH}$ ]. However, no evaluation has been conducted so far from the perspective of users after introducing this model. Studies examining the prevalence of disrespect and abuse in maternity care in Mozambique are scarce, especially in comparison to other countries in the region like Tanzania, South-Africa and Kenya [12, 15, 19, 20]. Recognizing that poor experiences for women might lead to less deliveries in the facilities and affect the quality of care by several pathways, this study aims to assess the experience of women giving birth in hospital in different settings in Maputo City and Province, Mozambique.

\section{Methods}

\section{Data collection tool}

A cross sectional descriptive survey was conducted between April and June 2018 in the Hospital Central de Maputo (HCM) and district hospitals of Manhiça and Marracuene in Maputo Province, Mozambique. HCM is a tertiary referral hospital with on average 20 deliveries a day. HCM is the only hospital in the country equipped to handle advanced operations, thereby serving as the last referral center for the entire country [21]. Manhica and Marracuene district hospital are secondary level hospitals with on average 10 and 5 deliveries a day, respectively. Self-referral and direct access is very common in all three facilities [22]. Exit-interviews were conducted with women leaving the hospital after delivery. The questionnaire consisted of the following components: socio-demographic characteristics, male involvement during labor and childbirth, intrapartum family planning (FP) services and experience of care. A normal delivery was defined as a vaginal delivery without the use of forceps, vacuum extraction or other medical interventions. A vaginal delivery involving a second degree tear or episiotomy was considered as a normal delivery. Experience of care was measured by using 23 verification criteria of disrespect and abuse, subdivided in the 7 categories, according to Bowser and Hill's landscape evidence review $[6,7,9,23]$. The questionnaire was translated into Portuguese and can be found in attachment (see 
Additional file 1). Four female data collectors, not involved in the women's care, were recruited and received a 1 week training regarding the study procedures, data collection tool and ethical research principles before embarking on data collection. All data collectors were trained to translate the questions from Portuguese to the local dialect (Changana) for participants who did not speak Portuguese.

\section{Sample size}

We wanted to measure the prevalence of disrespect and abuse in hospitals presenting different characteristics in this case district hospitals and a referral hospital. A single population proportion formula was used to estimate the sample size with assumptions of $5 \%$ precision, $95 \%$ confidence, and a $10 \%$ non-response rate. An assumption that $20 \%$ of the women would experience some form of disrespect or abuse was made, based on other studies [24, 25]. The final calculated sample size was 246 for each type of facility (district vs central hospital), which resulted in a total sample size of 592.

\section{Data collection procedure}

We conducted exit interviews with women staying at the maternity unit: all women aged 18-45 years who had delivered at the participating hospitals and who spoke Portuguese or Changana, were invited for an interview. Minors were not included because additional procedures would be required for ethical reasons (e.g. consent of parents, closer follow up).

Data collection continued until the required sample size was reached. Every morning the data collectors visited the post-partum maternity ward and contacted the head nurse to know which women were ready for discharge. These women were approached and invited to participate in the study. Women were invited after the morning round to avoid presence of health care providers. If they consented to participate the interview took place in a private room in the hospital. The questionnaire was set up in Open Data Kit software and tablet computers were used for data collection.

The questionnaire and recruitment procedure were thoroughly pilot-tested prior to data collection. After the pilot test small adaptations were made to the questions to improve comprehensibility.

\section{Ethical issues}

Ethical approval was obtained from the National Health Bioethics Committee of Mozambique, Health Bioethics Committee of Universidade Eduardo Mondlane (UEM), Hospital Central de Maputo (CIBS UEM\&HCM/0008-17) and from the Bioethics Committee of Ghent University (EC/2018/1319). All data collectors were trained in data collection procedures and ethical conduct. During the study data collectors were supervised on a daily basis by the principal investigator (AG). Written informed consent was obtained separately for each study participant. All participants were given detailed information about the study and contact details for further information, concerns or questions after participation.

Prior to the start of the study a meeting was organized with the management team of the delivery ward and maternity ward in all study sites to discuss the objective of the study and data collection procedures. Afterwards the management team introduced the study and research team (principal investigator, supervisor and data collectors) to the head nurse of the maternity ward.

\section{Data analysis}

All data was analyzed using the statistical software package R. Simple descriptive analysis was done to explore sociodemographic characteristics of the population. Differences in socio-demographic characteristics by place of delivery (district versus central hospital) were examined using Pearson's Chi squared test. Disrespect and abuse (D\&A) during childbirth were operationalized using the seven categories described in Bowser and Hill's landscape analysis [6] (see Table 2). In line with global consensus on describing and defining prevalence from the perspective and experience of the woman $[4,7]$, prevalence of each of D\&A category was calculated using the exit interview data. Women who reported experiencing one or more sub-components of D\&A were included in the overall prevalence measure.

While previous studies mostly focus on the outcome "experiencing at least one kind of abuse (yes or no)", we also took into account the number of forms of violence a woman experienced in our analysis. Most women experienced several forms of abuse, which would be masked by using a binary outcome variable for D\&A. The sum score of experiencing D\&A for each woman was calculated (varying from 0 to 7 ) and this variable was used as outcome variable in our negative binomial model. Independent variables for our model were chosen based on the hypotheses that women from certain subgroups (low educational level, single women, young women, women from rural areas) may be more likely to experience and/or report D\&A. The reported intercept (often labeled the constant) is the negative binomial regression estimate when all variables in the model are evaluated at zero [26].

\section{Results}

In total 932 women gave birth during the study period and 628 women were approached for an interview. The main reasons that some women were not invited to participate were their bad health condition or that they went home very soon after birth $(<24 \mathrm{~h})$. Of the 628 
women that were invited for the study, 572 participated. The main reason for not participating when invited was being < 18 years old $(n=36)$; other main reasons were not interested or not feeling well. During data cleaning 52 data entries had to be removed because of poor quality and/or incompleteness, resulting in a final sample of 520 women (see Fig. 1). The final dataset did not contain missing data. Sociodemographic characteristics of the participants can be found in Table 1.

\section{Sociodemographic characteristics}

In total 145 women participated in the study from the Manhiça district hospital, 73 from Marracuene district hospital and 302 from the central hospital $(=\mathrm{HCM})$. In the central hospital $28.48 \%$ of the women completed higher education and $10.60 \%$ finished secondary school. In the district hospitals $0.92 \%$ completed higher education and $1.38 \%$ secondary school. There was a significant difference between women who delivered in the district hospital compared to women who delivered in the central hospital regarding education, education of the partner, religion, age and type of delivery. Overall, women in the central hospital were higher educated, older and had more complicated pregnancies and caesarean sections (see Table 1).

\section{Experience of care}

Of the 302 women interviewed in HCM, 23.51\% $(n=72)$ reported at least one kind of abuse or disrespect during labor and/or delivery. In the district hospitals the percentage was significantly higher $\left(\mathrm{X}^{2}=159\right.$; d.f. $=1 ; p=$ 2e-36): $79.82 \%(n=174)$ of the women reported at least one form of disrespect or abuse. No significant difference was found in prevalence of disrespect and abuse between the two district hospitals $\left(x^{2}=0.36\right.$; d.f. $=1$; $p=0.55$ ). Design effect was 0.1904 , which is very low $($ rho $=-0.0054 ;$ deff $=0.1904)$. Between each district hospital and the central hospital the difference in prevalence of D\&A was significant as we expected at the start of the study: HCM/Manhiça $\left(\mathrm{x}^{2}=83\right.$; d.f. $=1$; $p=6.6 \mathrm{e}-20)$ and $\mathrm{HCM} /$ Marracuene $\left(\mathrm{x}^{2}=65\right.$; d.f. $=1 ; p=$ 7.7e-16).

The provision of non-confidential care (=lack of confidentiality), non-consented care (=services without permission) and abandonment were the most common types of disrespectful care during facility-based childbirth in the district hospital, followed by non-dignified care (=disrespectful treatment) (see Fig. 2). In the central hospital abandonment and non-dignified care were the most prevalent forms of D\&A (see Fig. 2). Prevalence of each type of disrespect and abuse can be found in Table 2 . Five women mentioned they gave birth alone because nobody came when they called for help (mentioned in category abandoned as "others"). Two women felt disrespected because they had to watch other women giving birth and two women felt disrespected because they had to clean up the bed after delivery (mentioned in category disrespectful treatment as "others").

\section{Experience of multiple forms of disrespect and abuse}

The average number of forms of D\&A each woman experienced was 1.70 in the district hospital and 0.31 in the central hospital. Women in the district hospitals experienced on average 1.4 more forms of D\&A compared to the central hospital, the difference between the two types of site was significant $(\mathrm{t}=20, \mathrm{df}=300, p$-value $<2 \mathrm{e}$ 16). While women in the central hospital experienced a maximum of 3 forms of D\&A, women in the district hospitals experienced a maximum of 5 forms of D\&A (see Fig. 3).

We explored which sociodemographic characteristics were associated with experiencing multiple forms of disrespect and abuse by building a binomial negative regression model for both the district hospital and central hospital. Taking into account the AICs (Akaike Information Criterion )[27], a model was selected with the number of forms of disrespect (varying from 0 to 7 ) as outcome variable and age, marital status, type of

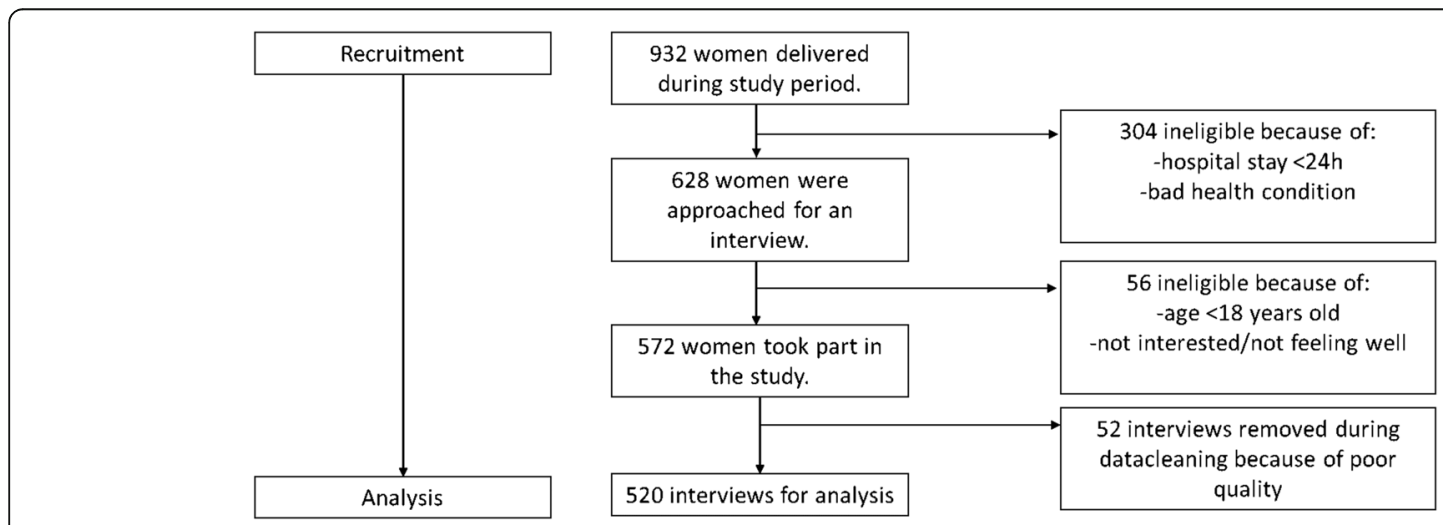

Fig. 1 Flow diagram showing process for inclusion in data analysis 
Table 1 Sociodemographic characteristics

\begin{tabular}{|c|c|c|c|c|c|}
\hline \multirow{2}{*}{$\begin{array}{l}\text { Site } \\
\text { Educational level woman** }\end{array}$} & \multicolumn{2}{|c|}{ District Hospitals $(N=218)$} & \multicolumn{2}{|c|}{ Central Hospital $(N=302)$} & \multirow{3}{*}{$\begin{array}{l}p \text {-value } \\
\left(x^{2} \text { test, } d f\right) \\
p=4 e-27 \\
\left(x^{2}=126, \text { d.f. }=3\right)\end{array}$} \\
\hline & $\mathrm{n}$ & $\%$ & $\mathrm{n}$ & $\%$ & \\
\hline No education & 40 & 18.35 & 3 & 0.01 & \\
\hline Primary school (at least 1 year) & 173 & 79.36 & 181 & 59.93 & \\
\hline Secondary school & 3 & 1.38 & 32 & 10.60 & \\
\hline Higher education & 2 & 0.92 & 86 & 28.48 & \\
\hline Marital Status & $n$ & $\%$ & $n$ & $\%$ & $p=0.38$ \\
\hline Single & 48 & 22.02 & 61 & 20.20 & \\
\hline In relationship & 167 & 76.61 & 241 & 79.80 & \\
\hline Divorced & 3 & 1.38 & 0 & 0 & \\
\hline Educational level partner** & $n$ & $\%$ & $\mathrm{n}$ & $\%$ & $p=2.8 \mathrm{e}-29$ \\
\hline No education & 7 & 3.21 & 1 & 0 & $\left(x^{2}=140\right.$, d.t. $\left.=4\right)$ \\
\hline Primary school (at least 1 year) & 135 & 61.93 & 132 & 16.23 & \\
\hline Secondary school & 3 & 1.38 & 28 & 9.60 & \\
\hline Higher education & 11 & 5.05 & 126 & 41.39 & \\
\hline Don't know & 62 & 28.44 & 15 & 4.97 & \\
\hline Religion** & $n$ & $\%$ & $\mathrm{n}$ & $\%$ & $p=4.5 \mathrm{e}-15$ \\
\hline Catholic & 25 & 11.47 & 74 & 24.50 & \\
\hline Islam & 6 & 2.75 & 31 & 10.26 & \\
\hline Zione & 58 & 26.61 & 17 & 5.63 & \\
\hline Protestant & 91 & 41.74 & 131 & 43.38 & \\
\hline Independent Christian church & 33 & 15.14 & 27 & 8.94 & \\
\hline No religion & 3 & 1.38 & 0 & 0 & \\
\hline Others & 2 & 0.92 & 22 & 7.29 & \\
\hline $\operatorname{Age}^{* *}$ & $n$ & $\%$ & $\mathrm{n}$ & $\%$ & $p=0.00045$ \\
\hline $18-21$ & 66 & 30.28 & 46 & 15.23 & \\
\hline$>21-25$ & 48 & 22.02 & 71 & 23.51 & \\
\hline$>25-35$ & 80 & 36.70 & 148 & 49.01 & \\
\hline$>35$ & 24 & 11.01 & 37 & 12.25 & \\
\hline Type of delivery** & $\mathrm{n}$ & $\%$ & $\mathrm{n}$ & $\%$ & $p=7 \mathrm{e}-10$ \\
\hline Normal & 194 & 88.99 & 195 & 64.57 & \\
\hline With complications & 16 & 7.34 & 49 & 19.21 & \\
\hline Caesarean section & 8 & 3.67 & 58 & 16.23 & \\
\hline
\end{tabular}

Levels of significance with the chi-square test: $=p<0.1 ;{ }^{*}=p<0.05 ;{ }^{* *}=p<0.01$

delivery, educational level and parity as predictors. Religion and educational level of the husband were also included as covariates but eliminated during model selection as these sociodemographic characteristics were not significant and reduced validity of the model. Table 3 shows the descriptive statistics of the explanatory variables (=predictors).

In the district hospital having a caesarean section decreased the number of disrespect with 1.26 (see Table 4). In the central hospital (see Table 5) having a delivery with complications increased the number of D\&A with 0.65. Also having completed primary education increased the number of D\&A with 0.80 . Also age was a significant predictor, younger women experienced significantly more D\& A. Every year older decreased the number of D\&A with 0.05 (see Table 5).

\section{Role of the partner}

One man was present during labor and delivery in Marracuene district hospital, and no men were present in Manhiça. In HCM no men were present, this is officially not permitted in this hospital.

Women were asked if they would like to have their husband as their companion during labor and/or delivery 


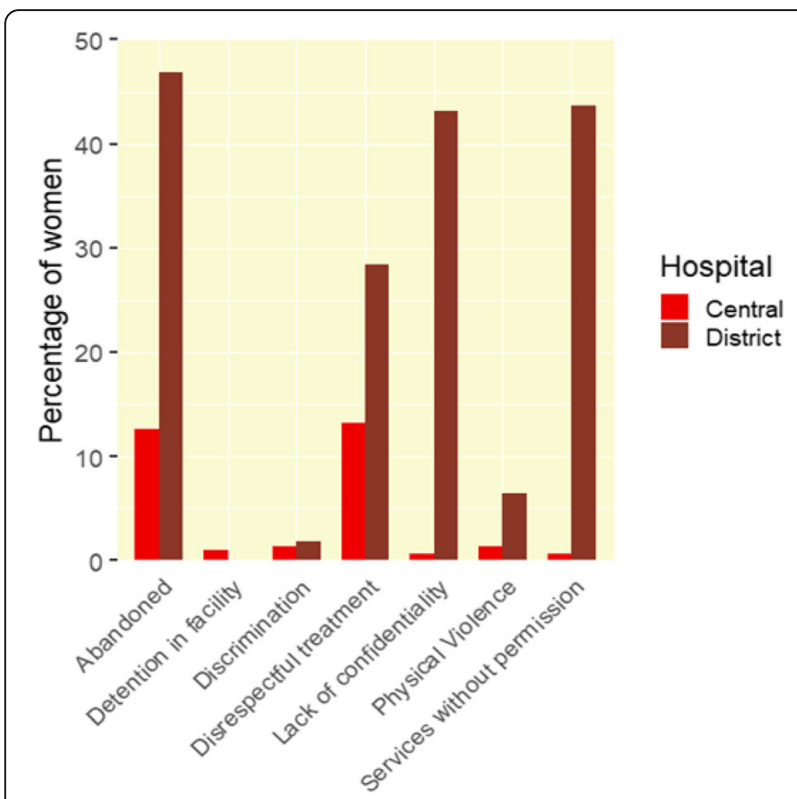

Fig. 2 Percentage of women experiencing D\&A by category in the district hospitals and central hospital

(if allowed). The results showed that $79.47 \%(n=240)$ of the women in HCM would like their husband to be present and $62.84 \%(n=137)$ of the women in the district hospitals. The women were also asked if they thought their husbands would be willing to be their companion, $72.85 \%(n=220)$ of the women in HCM and $41.74 \%$ ( $n=$ 91) of the women in the district hospitals believed their husbands would like to accompany them.

\section{Family planning in the immediate postpartum}

Family planning was discussed by the provider with $8.94 \%(n=27)$ of the women during their stay in HCM and with $15.60 \%(n=34)$ of the women in the district hospitals. Of the women in HCM $0.99 \%(n=3)$ received a contraceptive method. In the district hospitals $1.83 \%$ $(n=4)$ of the women received a contraceptive method. Which methods were discussed and provided can be found in Table 6.

\section{Discussion}

The prevalence of disrespect and abuse in our study was similar to the prevalence in other countries in the region: $23.51 \%$ in the central hospital and $79.82 \%$ in the district hospitals. Studies from Ethiopia, Kenya and Tanzania report D\&A prevalence rates between 20 and $70 \%[9,12,17,20]$. However, it may be problematic to focus only on overall prevalence of D\&A as an outcome, as this covers a wide range of forms of D\&A that are very different in nature (e.g. injections without permission versus slapping and beating). In this study we found that more severe forms of abuse such as detention in the facility (for failure of paying) and physical violence (such as slapping) are almost non-existent in the study sites in Mozambique, while studies conducted in other countries often report much higher figures. For example, a systematic review of D\&A in Ethiopia estimated a prevalence of $13 \%$ for physical abuse and 3.2\% for detention in the facility [28]. The implementation of the "Iniciativa Maternidade Modelo" might have contributed to this positive result in Maputo City and Maputo Province and further efforts should focus on reducing abandonment (when the patient is being left alone) and disrespectful treatment (being shouted/scolded at), which continue to be prevalent.

The occurrence of D\&A in maternity care services is often considered as a marker for quality of care: it might affect quality of care in both terms of discouraging women to deliver in facilities but also directly through inadequate monitoring during childbirth (eg. infrequent fetal monitoring during labour and delivery, or absence of a skilled provider for resuscitation of the newborn or to intervene in case of bleeding of the mother) [14]. Several participants in our study reported they delivered alone in the health facility, which imposes a serious risk on both mother and child. This might also indicate that the number of women delivering without a skilled birth attendant is probably under reported in the region. Mozambique is struggling with a weak health system, characterized by poor health infrastructure, shortage of providers and insufficient supervision [29]. Certain forms of D\&A (abandonment and lack of privacy) we found to be common might be triggered or worsened by resource scarcity within the health system. The inadequate health system resources (lack of separate rooms, insufficient skilled providers) are probably a major contributing factor to certain forms of D\&A and prevention should be oriented at this level.

Stigmatization and emotional abuse of women by providers (discrimination of primigravidas due to being unexperienced, slanderous remarks, lack of privacy regarding age) are also a prevalent problem in maternity care in Mozambique, according to our results. Discrimination and stigmatization of certain subgroups in health care settings have been studied mostly in high income countries. The problem has much less been studied in low income countries and has had a strong focus on minority groups and HIV stigmatization [30, 31]. The role of medical education (e.g. training to shape the attitudes of providers) in prevention of discrimination in health care settings may be well recognized, especially in highincome countries, but it is inadequately explored in the context of D\&A [10, 32]. On a global level, countries with strong colonial roots often have a health system culture where providers morally instruct and educate 
Table 2 Prevalence different forms of D\&A

\begin{tabular}{|c|c|c|c|c|}
\hline \multirow[t]{2}{*}{ Site } & \multicolumn{2}{|c|}{ District Hospital } & \multicolumn{2}{|c|}{ Central Hospital } \\
\hline & $\mathrm{n}$ & $\%$ & $\mathrm{n}$ & $\%$ \\
\hline \multicolumn{5}{|l|}{ Services without permission } \\
\hline Caesarean section & 1 & 0.46 & 1 & 0.3 \\
\hline Episiotomy & 1 & 0.46 & 0 & 0.0 \\
\hline Stitching & 14 & 6.42 & 0 & 0.0 \\
\hline Blood transfusion & 0 & 0.00 & 0 & 0.0 \\
\hline Sterilization & 0 & 0.00 & 0 & 0.0 \\
\hline Injection & 82 & 37.61 & 0 & 0.0 \\
\hline Shaving & 0 & 0.00 & 0 & 0.0 \\
\hline Others & 1 & 0.46 & 1 & 0.3 \\
\hline No & 123 & 56.42 & 300 & 99.3 \\
\hline \multicolumn{5}{|l|}{ Lack of confidentiality } \\
\hline Disease (HIV) & 1 & 0.46 & 0 & 0.0 \\
\hline Age & 3 & 1.38 & 0 & 0.0 \\
\hline Medical history & 0 & 0.00 & 0 & 0.0 \\
\hline Absence or position of the father & 0 & 0.00 & 0 & 0.0 \\
\hline During labour and delivery & 89 & 40.83 & 1 & 0.3 \\
\hline Others & 1 & 0.46 & 1 & 0.3 \\
\hline No & 124 & 56.88 & 300 & 99.3 \\
\hline \multicolumn{5}{|l|}{ Disrespectful treatment } \\
\hline Threatened with C-section & 5 & 2.29 & 7 & 2.3 \\
\hline Scolded, shouted at & 57 & 26.15 & 30 & 9.9 \\
\hline Slanderous remarks & 6 & 2.75 & 2 & 0.7 \\
\hline Blamed or intimidated & 3 & 1.38 & 1 & 0.3 \\
\hline Others & 1 & 0.46 & 7 & 0.3 \\
\hline No & 156 & 71.56 & 262 & 86.8 \\
\hline \multicolumn{5}{|l|}{ Physical Violence } \\
\hline Beaten, slapped or pinched & 0 & 0.00 & 0 & 0.0 \\
\hline Tied down or restrained & 0 & 0.00 & 0 & 0.0 \\
\hline Episiotomy sutured without anesthesia & 14 & 6.42 & 2 & 0.7 \\
\hline Sexually abused by health worker & 0 & 0.00 & 0 & 0.0 \\
\hline Others & 0 & 0.00 & 2 & 0.7 \\
\hline No & 204 & 93.58 & 298 & 98.7 \\
\hline \multicolumn{5}{|l|}{ Discrimination } \\
\hline Ethnicity & 0 & 0.00 & 0 & 0.0 \\
\hline Young and unexperienced & 3 & 1.38 & 0 & 0.0 \\
\hline Single motherhood status & 0 & 0.00 & 0 & 0.0 \\
\hline HIV sero-positive status & 1 & 0.46 & 0 & 0.0 \\
\hline Low socio-economic status & 0 & 0.00 & 2 & 0.7 \\
\hline Others & 0 & 0.00 & 2 & 0.7 \\
\hline No & 214 & 98.17 & 298 & 98.7 \\
\hline \multicolumn{5}{|l|}{ Detention in facility } \\
\hline Unpaid bills mother & 0 & 0.00 & 1 & 0.3 \\
\hline Unpaid bills baby & 0 & 0.00 & 0 & 0.0 \\
\hline
\end{tabular}


Table 2 Prevalence different forms of D\&A (Continued)

\begin{tabular}{|c|c|c|c|c|}
\hline \multirow[t]{2}{*}{ Site } & \multicolumn{2}{|c|}{ District Hospital } & \multicolumn{2}{|c|}{ Central Hospital } \\
\hline & $\mathrm{n}$ & $\%$ & $\mathrm{n}$ & $\%$ \\
\hline Others & 0 & 0.00 & 2 & 0.7 \\
\hline No & 218 & 100.00 & 299 & 99.0 \\
\hline \multicolumn{5}{|l|}{ Abandoned } \\
\hline Left alone unattended too often & 76 & 34.86 & 22 & 7.3 \\
\hline Denied birth companion & 17 & 7.80 & 1 & 0.3 \\
\hline Birth attendant didn't intervene in urgent situations & 0 & 0.00 & 1 & 0.3 \\
\hline Neglected because staff was exhausted & 31 & 14.22 & 5 & 1.7 \\
\hline Others & 5 & 2.29 & 11 & 3.6 \\
\hline No & 116 & 53.21 & 264 & 87.4 \\
\hline
\end{tabular}

their patients [14], which might contribute to the occurrence of D\&A in Mozambique. This is in line with research that suggest that nurses' and midwives' inferiority in medical hierarchy and lack of power within their own professional and organizational structures might contribute to their need to dominate and control even more disempowered patients $[13,33]$. When designing interventions to prevent $D \& A$, a participatory approach with providers will be needed to explore the roots of their abusive behaviors towards women and identify ways to overcome them.

The overall prevalence of D\&A in the district hospitals was much higher compared to the central hospital

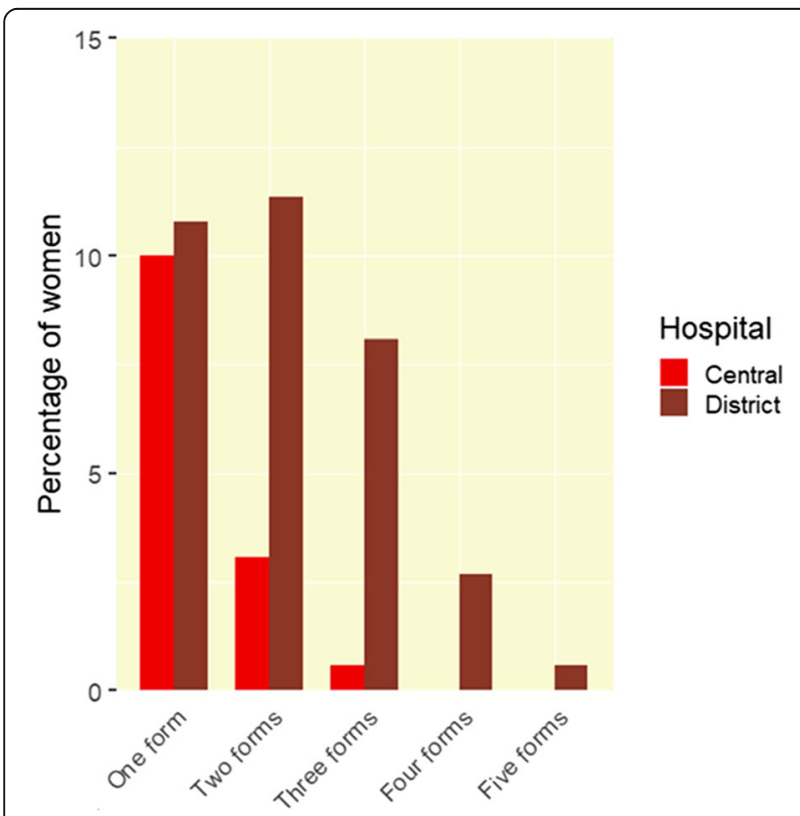

Fig. 3 Percentage of women experiencing multiple forms of D\&A in the district hospitals and central hospital
(79.8\% vs $23.5 \%)$. Furthermore, we could demonstrate that women in the district hospitals more often experience a combination of different forms of disrespect and abuse compared to the central hospital. In our study the lower D\&A prevalence in the central hospital compared to the district hospitals might be related to the fact that providers work under better circumstances in the central hospital. The central hospital is a teaching hospital with more supervision and control mechanisms than the district hospitals (e.g. extensive maternal death audits and

Table 3 Descriptive statistics explanatory variables (predictors)

\begin{tabular}{|c|c|c|c|c|}
\hline & \multicolumn{4}{|c|}{ Number of forms of violence } \\
\hline & \multicolumn{2}{|c|}{ District Hospitals } & \multicolumn{2}{|c|}{ Central Hospital } \\
\hline & Mean & SD & Mean & SD \\
\hline \multicolumn{5}{|l|}{ Educational level } \\
\hline Primary level & 1.72 & 1.25 & 0.22 & 0.50 \\
\hline Secondary or more & 1.17 & 0.98 & 0.44 & 0.74 \\
\hline \multicolumn{5}{|l|}{ Number or pregnancies } \\
\hline Primigravida & 2.02 & 1.38 & 0.41 & 0.70 \\
\hline Multigravida & 1.61 & 1.20 & 0.27 & 0.57 \\
\hline \multicolumn{5}{|l|}{ Type of delivery } \\
\hline Normal delivery & 1.76 & 1.22 & 0.27 & 0.61 \\
\hline Delivery with complications & 1.62 & 1.45 & 0.47 & 0.68 \\
\hline Cesarean section & 0.50 & 0.76 & 0.31 & 0.57 \\
\hline \multicolumn{5}{|l|}{ Civil state } \\
\hline Single & 1.7 & 1.13 & 0.31 & 0.62 \\
\hline In relationship & 1.69 & 1.28 & 0.30 & 0.61 \\
\hline \multicolumn{5}{|l|}{ Age } \\
\hline$<=21$ years & 1.71 & 1.33 & 0.48 & 0.78 \\
\hline$>21$ and $=<25$ years & 1.88 & 1.25 & 0.34 & 0.63 \\
\hline$>25$ and $=<35$ years & 1.57 & 1.17 & 0.26 & 0.56 \\
\hline$>35$ years & 1.75 & 1.29 & 0.22 & 0.53 \\
\hline
\end{tabular}


Table 4 Binomial negative regression model D\&A in District hospitals

\begin{tabular}{|c|c|c|c|c|}
\hline & Estimate & Std. Error & z-value & $p$ \\
\hline \multicolumn{5}{|l|}{ Effect: } \\
\hline Intercept & 0.55 & 0.15 & 3.58 & $0.00034^{* *}$ \\
\hline Number of pregnancies & -0.01 & 0.03 & -0.23 & 0.82 \\
\hline Having a C-section & -1.26 & 0.50 & -2.51 & $0.01^{*}$ \\
\hline Having delivery with complications & -0.06 & 0.20 & -0.31 & 0.76 \\
\hline Having completed primary school & 0.42 & 0.38 & -1.09 & 0.27 \\
\hline Being Single & 0.01 & 0.13 & 0.12 & 0.91 \\
\hline Age & 0.00 & 0.01 & 0.31 & 0.76 \\
\hline
\end{tabular}

Levels of significance:. $=p<0.1 ;{ }^{*}=p<0.05 ;{ }^{* *}=p<0.01$

academic meetings), and in general the maternity care system in Maputo City is better resourced than the rest of the country [34].

There is no consensus in the literature on the role sociodemographic and institutional factors play in the actual prevalence or reporting of D\&A [9, 13, 19, 35]. Moreover, the influence of these factors might be very context specific [10]. This was confirmed in our study: sociodemographic factors played a different role in the central hospital compared to the district hospitals. In our study women with a secondary degree experience and/or report more forms of D\&A [12]. This relationship might be related to the fact that these women expect higher standards of care and more easily recognize abusive behavior $[12,36]$. Echoing the results of other studies, women in our study who had a delivery with complications reported more D\&A [37]. Age was a protective factor against D\&A in the central hospital. Several qualitative studies report that especially young and unexperienced women experience D\&A due to power dynamics and low status [38, 39]. But they might also less easily recognize and report unacceptable behavior of providers, which might explain the contradicting findings in the literature. Nevertheless, more qualitative data from both women and providers will be needed to explore contributing factors regarding D\&A in the Mozambican health system and specific context.
Labor companionship is a key component of providing respectful maternity care and has been included as one of the WHO standards for improving the quality of maternal and newborn care in health facilities [40]. Despite the benefits of a companion of choice throughout labor, implementation of this approach is not universal [41]. In Mozambique all maternities are officially obliged to allow birth companions since the introduction of the Model Maternity Initiative in 2017. However, in practice there are different rules depending on the provider (e.g. only women are allowed, no traditional birth attendants, only during the day, not able to switch) (experience in the field]. In most facilities in Mozambique it is strictly forbidden to allow male partners as birth companions during labor and delivery. This rule is partly linked with an overall lack of privacy on maternity wards (e.g. women deliver in beds next to each other in one room), which is perceived as more problematic when men are allowed to be present. However, as public facilities are improving more maternities now have separate rooms, and also in very small facilities privacy can often be guaranteed due to low numbers of births. Recognizing that the Respectful Maternity Care Charter and $\mathrm{MoH}$ policy state that women have the right to choose their own birth companion it is then contradictory to only allow female birth companions [42]. Also the World Health Organization recommends in their intrapartum guidelines that a parturient woman should be

Table 5 Binomial negative regression model D\&A in central hospital

\begin{tabular}{|c|c|c|c|c|}
\hline & Estimate & Std. Error & $z$-value & $p$ \\
\hline \multicolumn{5}{|l|}{ Effect: } \\
\hline Intercept & -0.12 & 0.60 & -0.19 & 0.85 \\
\hline Number of pregnancies & -0.03 & 0.12 & -0.26 & 0.80 \\
\hline Having a C-section & 0.23 & 0.30 & 0.77 & 0.44 \\
\hline Having delivery with complications & 0.65 & 0.28 & 2.34 & $0.02^{*}$ \\
\hline Having completed primary school & 0.80 & 0.23 & 3.41 & $0.00064^{* *}$ \\
\hline Being Single & -0.32 & 0.29 & -1.10 & 0.27 \\
\hline Age & -0.05 & 0.30 & -1.09 & $0.04^{*}$ \\
\hline
\end{tabular}

Levels of significance:. $=p<0.1 ;{ }^{*}=p<0.05 ;{ }^{* *}=p<0.01$ 
Table 6 Family planning methods

\begin{tabular}{|c|c|c|c|c|}
\hline \multirow[t]{2}{*}{ Site } & \multicolumn{2}{|c|}{ District Hospitals } & \multicolumn{2}{|c|}{ Central Hospital } \\
\hline & $\mathrm{n}$ & $\%$ & $\mathrm{n}$ & $\%$ \\
\hline \multicolumn{5}{|l|}{ Methods discussed } \\
\hline Female condom & 14 & 6.42 & 19 & 6.29 \\
\hline Male condom & 12 & 5.50 & 18 & 5.96 \\
\hline Lactation amenorrhea Method & 0 & 0.00 & 1 & 0.33 \\
\hline Oral contraceptives & 29 & 13.30 & 13 & 4.30 \\
\hline Injectable contraceptives & 24 & 11.01 & 11 & 3.64 \\
\hline IUD & 16 & 7.34 & 18 & 5.96 \\
\hline Implant & 26 & 11.93 & 24 & 7.95 \\
\hline Sterilisation & 0 & 0.00 & 7 & 2.32 \\
\hline Others & 1 & 0.46 & 2 & 0.66 \\
\hline \multicolumn{5}{|l|}{ Methods received } \\
\hline Female condom & 1 & 0.46 & 0 & 0 \\
\hline Male condom & 1 & 0.46 & 0 & 0 \\
\hline Breastfeeding & 0 & 0.00 & 0 & 0 \\
\hline Oral contraceptives & 0 & 0.00 & 1 & 0.33 \\
\hline Injectable contraceptives & 0 & 0.00 & 0 & 0 \\
\hline IUD & 0 & 0.00 & 0 & 0 \\
\hline Implant & 1 & 0.46 & 0 & 0 \\
\hline Sterilisation & 1 & 0.46 & 2 & 0.66 \\
\hline
\end{tabular}

encouraged to have a supportive companion she trusts and can feel at ease with in labor and birth [5, 43].

Our study found that a majority of women were in favor of involving their male partner as birth companion and many also believe their partners would be in favor. The desire of women to involve their male partner should be taken into consideration by maternities and might be a motive to reconsider current restrictions, where privacy can be guaranteed. Another argument for allowing men on maternity wards is that research suggests that disrespectful care would be less frequent if partners were present [44-46]. Birth companions in general are a protective factor against $\mathrm{D} \& \mathrm{~A}[13,19]$, and there is some evidence that bringing in the male partner might further protect the women against experiencing D\&A. A study from Tanzania showed that male partners of women who experience abuse during labor or delivery find it easier to request better care or lodge a complaint than the women themselves [46]. Qualitative studies on experiences of men who have attended the births of their children in Malawi also showed that with a supportive environment and positive attitude of the midwives, it is possible to involve male partners during childbirth and for this to be a positive experience for both men and women [47, 48]. Further research is needed to explore the feasibility of allowing men in the delivery room in Mozambique and to examine potential strategies that create the ideal conditions for men to be present during labor and birth as the birth companion. It would also be interesting to examine whether involving men in maternity care might have an impact on the prevalence of disrespect and abuse during childbirth.

Offering modern contraception services as part of care provided during childbirth increases postpartum contraceptive use and is likely to reduce both unintended pregnancies and pregnancies that are too closely spaced [49]. It is recommended by the WHO standards for improving the quality of maternal and newborn care in health facilities [40] but very often neglected in studies examining quality of childbirth care [50]. Our study showed that both in the district hospitals and the central hospital the number of women receiving counselling about family planning was very low (17 and 9\% respectively). For women with limited access to health care in facilities, delivery at a facility affords a unique opportunity to address their fertility intentions and need for contraception: it does not require a return visit that may be prohibitively expensive or inconvenient. Previous studies have shown that in the year following childbirth, many women want to postpone or avoid further births, but do not use a contraceptive method [51]. Offering family planning counselling before women leave the hospital might be an important and unique opportunity to protect women from an unplanned pregnancy, as only a minority of women (40-44\%) return to the health facility for a postnatal care visit in Mozambique [18, 52]. Evidence has shown that discussing family planning before discharge from the maternity ward is an effective intervention to increase the uptake of family planning methods postpartum [53-56]. Mozambique has a comprehensive strategy to reduce the unmet need for family planning including guidelines for integrating family planning counselling and provision of contraceptives across the health service including during the intrapartum period [57-60]. However, increased attention is required to translate this policy into practice in order to improve uptake of family planning services in the post-partum period.

\section{Limitations}

Currently there is a lack of standardized definitions, instruments, and study methods to quantify D\&A in childbirth facilities, which affects the generalizability and comparability of results [7]. A validated instrument, taking into account the severity of each form of abuse, is needed if we want to continue to compare overall prevalence of D\&A across different countries and/or regions. Furthermore some reported forms of D\&A might not actually constitute mistreatment: for example, giving an injection without permission or stitching a first degree tear without anesthesia might be justified under certain medical 
conditions. A recent qualitative evidence synthesis also showed that RMC is a broader concept than merely the absence of mistreatment, although the two are intertwined [61]. While qualitative studies show that provider's and women's views on respectful maternity care are widely consistent globally, further research is needed to assess the validity and responsiveness of quantitative indicators to measure RMC [61].

Previous studies have shown that the factors that contribute to D\&A in maternity care services and potential prevention measures are very context specific, which was confirmed in our study. We acknowledge that our study results cannot be generalized to other settings and further studies in different contexts in Mozambique are needed. Nevertheless we were able to show that D\&A is a prominent problem in the country despite some significant quality improvement programs in maternity care over the last years.

We did not include minors, which is a limitation of our study. Data suggest that D\&A and especially discrimination happen more often with adolescents, and our study found that increased age was protective against D\&A. A follow-up study focusing on the occurrence of D\&A in this specific group is recommended. In addition, our study was conducted inside the health institution, where social desirability bias can underestimate the occurrence of D\&A. A community-based study might give women more freedom to express their feelings and report their experiences without fear, and eliminate this social desirability bias [62].

\section{Conclusions}

The overall prevalence of disrespect and abuse in our study was similar to the prevalence in other countries in the region but the more severe forms of abuse such as detention in the facility (for failure of paying) and physical violence (such as slapping) are almost nonexistent. Occurrence of disrespect and abuse was much higher in the district hospitals. The majority of women were in favor of involving their male partner as birth companion and further research is needed to explore the feasibility of allowing men in the delivery room. Both in the district hospitals and the central hospital the number of women receiving counselling about family planning was very low. Investing in intrapartum counselling for family planning is currently a missed opportunity for improving the uptake of contraception in the country.

\section{Supplementary information}

Supplementary information accompanies this paper at https://doi.org/10. 1186/s12884-019-2532-z.

Additional file 1. Questionnaire.

\section{Abbreviations}

ANC: Antenatal Care; D\&A: Disrespect and Abuse; FP: Family Planning; HCM: Hospital Central de Maputo; MCHIP: Maternal and Child Health Integrated Program; MDGs: Millennium Development Goals; MMR: Maternal Mortality Ratio; MNH: Maternal and Newborn Health; MoH: Ministry of Health; RMC: Respectful Maternity Care; SDGs: Sustainable Development Goals; UEM: Universidade Eduardo Mondlane; WHO: World Health Organization

\section{Acknowledgements}

We would like to thank all the women who were willing to be interviewed for their valuable contribution. Thank you to the data collectors for interviewing these women. We want to thank the facility directors and health providers for their assistance. We also would like to thank the colleagues of the International Centre for Reproductive Health Mozambique and Belgium for their advice and encouragement.

\section{Authors' contributions}

AG developed the study protocol, collected data and drafted the manuscript. HM, EC and JP assisted in developing the data collection instruments and data collection. OD, KR, SG and NO assisted in data analysis and interpretation of the results. All authors revised the manuscript critically and read and approved the final manuscript.

\section{Funding}

This study was funded by a VLADOC PhD scholarship from the Flemish Inter-University Council (VLIR-UOS Belgium) and additional funding from the Global Minds programme. The content of this manuscript is solely the responsibility of the authors and does not necessarily represent the official views of VLIR-UOS. The funding organization has no role in the design of the study, data collection, analysis, interpretation of data, and in writing the manuscript.

Availability of data and materials

The datasets used and/or analyzed during the current study are available from the corresponding author upon reasonable request.

Ethics approval and consent to participate

Ethical approval for the study was obtained by both the National Health Bioethics Committee of Mozambique and Bioethics Committee of Ghent University. All participants gave their written consent.

Consent for publication

Not applicable

\section{Competing interests}

The authors declare that they have no competing interests.

\section{Author details}

${ }^{1}$ International Centre for Reproductive Health, Department of Public Health and Primary Care, Ghent University, Corneel Heymanslaan 10, entrance 75, UZP 114, 9000 Ghent, Belgium. ${ }^{2}$ International Centre for Reproductive Health - Mozambique, Rua das Flores no 34, Impasse 1085, /87 Maputo,

Mozambique. ${ }^{3}$ Faculty of Medicine, Department of Obstetrics/Gynecology, Eduardo Mondlane University, Av. Salvador Allende, 57 Maputo,

Mozambique.

Received: 31 May 2019 Accepted: 24 September 2019

Published online: 22 October 2019

\section{References}

1. Say L, Chou D, Gemmill A, Tunçalp Ö, Moller A-B, Daniels J, et al. Global causes of maternal death: a WHO systematic analysis. Lancet Glob Heal. 2014;2:e323-33. https://doi.org/10.1016/S2214-109X(14)70227-X

2. Lunze K, Higgins-Steele A, Simen-Kapeu A, Vesel L, Kim J, Dickson K. Innovative approaches for improving maternal and newborn health--a landscape analysis. BMC Pregnancy Childbirth. 2015;15:337. https://doi.org/ 10.1186/s12884-015-0784-9.

3. Souza JP, Gülmezoglu AM, Vogel J, Carroli G, Lumbiganon P, Qureshi Z, et al. Moving beyond essential interventions for reduction of maternal mortality (the WHO Multicountry Survey on Maternal and Newborn Health): 
a cross-sectional study. Lancet (London, England). 2013;381:1747-55. https://doi.org/10.1016/S0140-6736(13)60686-8.

4. Akachi Y, Tarp F, Kelley E, Addison T, Kruk ME. Measuring quality-of-care in the context of sustainable development goal 3: a call for papers. Bull World Health Organ. 2016;94:160-160A. https://doi.org/10.2471/BLT.16.170605.

5. WHOI WHO recommendations: intrapartum care for a positive childbirth experience. WHO. 2018. http://www.who.int/reproductivehealth/ publications/intrapartum-care-guidelines/en/. Accessed 15 June 2018.

6. Bowser D, Hill K. Exploring evidence for disrespect and abuse in facilitybased childbirth. Report of a landscape analysis. Bethesda, MD: USAIDTRAction Project, University Research Corporation, LLC, and Harvard School of Public Health; 2010.

7. Sando D, Abuya T, Asefa A, Banks KP, Freedman LP, Kujawski S, et al. Methods used in prevalence studies of disrespect and abuse during facility based childbirth: lessons learned. Reprod Health. 2017;14:127. https://doi. org/10.1186/s12978-017-0389-z.

8. The prevention and elimination of disrespect and abuse during facilitybased childbirth. http://apps.who.int/iris/bitstream/10665/134588/1/WHO_ RHR_14.23_eng.pdf?ua=1\&ua=1. Accessed 25 Jan 2018.

9. Okafor II, Ugwu EO, Obi SN. Disrespect and abuse during facility-based childbirth in a low-income country. Int J Gynecol Obstet. 2015;128:110-3. https://doi.org/10.1016/j.jigo.2014.08.015.

10. Rosen HE, Lynam PF, Carr C, Reis V, Ricca J, Bazant ES, et al. Direct observation of respectful maternity care in five countries: a cross-sectional study of health facilities in east and southern Africa. BMC Pregnancy Childbirth. 2015;15:306. https://doi.org/10.1186/s12884-015-0728-4

11. Promoting Respectful Maternity Care in Mozambique 1. http://www.mchip. net/sites/default/files/Promoting_RMC_in_Mozambique.pdf. Accessed 11 Oct 2017.

12. Kruk ME, Kujawski S, Mbaruku G, Ramsey K, Moyo W, Freedman LP. Disrespectful and abusive treatment during facility delivery in Tanzania: a facility and community survey. Health Policy Plan. 2018;33:e26-33. https://doi.org/10.1093/heapol/czu079.

13. Sheferaw ED, Bazant E, Gibson H, Fenta HB, Ayalew F, Belay TB, et al. Respectful maternity care in Ethiopian public health facilities. Reprod Health. 2017;14:60. https://doi.org/10.1186/s12978-017-0323-4.

14. Miller S, Lalonde A. The global epidemic of abuse and disrespect during childbirth: history, evidence, interventions, and FIGO's mother-baby friendly birthing facilities initiative. Int J Gynecol Obstet. 2015;131:S4952. https://doi.org/10.1016/J.JJGO.2015.02.005.

15. Bohren MA, Vogel JP, Hunter EC, Lutsiv O, Makh SK, Souza JP, et al. The mistreatment of women during childbirth in health facilities globally: a mixed-methods systematic review. PLoS Med. 2015;12: e1001847. https://doi.org/10.1371/journal.pmed.1001847.

16. Ratcliffe HL, Sando D, Lyatuu GW, Emil F, Mwanyika-Sando M, Chalamilla G, et al. Mitigating disrespect and abuse during childbirth in Tanzania: an exploratory study of the effects of two facility-based interventions in a large public hospital. Reprod Health. 2016;13:79. https://doi.org/10.1186/s12978016-0187-z.

17. Sando D, Ratcliffe H, McDonald K, Spiegelman D, Lyatuu G, MwanyikaSando $\mathrm{M}$, et al. The prevalence of disrespect and abuse during facility-based childbirth in urban Tanzania. BMC Pregnancy Childbirth. 2016;16:236. https://doi.org/10.1186/s12884-016-1019-4

18. MISAU, INE. Inquérito de Indicadores de Imunização, Malária e HIV/SIDA em Moçambique (IMASIDA) 2015: Relatório de Indicadores Básicos. Maputo. 2016.

19. Abuya T, Warren CE, Miller N, Njuki R, Ndwiga C, Maranga A, et al. Exploring the prevalence of disrespect and abuse during childbirth in Kenya. PLoS One. 2015;10:e0123606. https://doi.org/10.1371/journal.pone.0123606.

20. Asefa A, Bekele D. Status of respectful and non-abusive care during facilitybased childbirth in a hospital and health centers in Addis Ababa, Ethiopia. Reprod Health. 2015;12:33. https://doi.org/10.1186/s12978-015-0024-9.

21. Snyder E, Amado V, Jacobe M, Sacks GD, Bruzoni M, Mapasse D, et al. General surgical services at an urban teaching hospital in Mozambique. J Surg Res. 2015;198:340-5.

22. WHO Levels of Health Services. https:/www.who.int/management/facility/ ReferralDefinitions.pdf. Accessed 6 June 2019.

23. Reis V, Senior R, Advisor T, Deller B, Senior M, Advisor M, et al. Respectful Maternity Care Country experiences Survey Report. 2012. http://reprolineplus.org/system/files/resources/RMCSurvey Report_0.pdf.

24. Lwanga $H$, Atuyambe L, Sempewo $H$, Lumala A, Byaruhanga RNB. An exploratory study of men's companionship, perceptions and experiences during pregnancy and delivery in Uganda. BMC Pregnancy Childbirth. 2017; 17:196. https://doi.org/10.1186/s12884-017-1385-6.

25. Modarres NV. Couples' attitudes to the husband's presence in the delivery room during childbirth. East Mediterr Health J. 2005;11:828-34 http://www. ncbi.nlm.nih.gov/pubmed/16700400.

26. Hilbe JM. Negative Binomial Regression Second Edition-Negative Binomial Regression, 2nd Edition www.cambridge.org. Accessed 3 Nov 2018.

27. Wang H, Peng J, Wang B, Lu X, Zheng JZ, Wang K, et al. Inconsistency between univariate and multiple logistic regressions. Shanghai Arch Psychiatry. 2017;29:124-8. https://doi.org/10.11919/j.issn.1002-0829.217031.

28. Kassa ZY, Husen S. Disrespectful and abusive behavior during childbirth and maternity care in Ethiopia: a systematic review and meta-analysis. BMC Res Notes. 2019;12:83. https://doi.org/10.1186/s13104-019-4118-2.

29. Biza A, Jille-Traas I, Colomar M, Belizan M, Requejo Harris J, Crahay B, et al. Challenges and opportunities for implementing evidence-based antenatal care in Mozambique: a qualitative study. BMC Pregnancy Childbirth. 2015; 15:200. https://doi.org/10.1186/s12884-015-0625-x.

30. Turan JM, Miller S, Bukusi EA, Sande J, Cohen CR. HIV/AIDS and maternity care in Kenya: how fears of stigma and discrimination affect uptake and provision of labor and delivery services. AIDS Care. 2008;20:938-45. https://doi.org/10.1080/09540120701767224.

31. Sando D, Kendall T, Lyatuu G, Ratcliffe H, McDonald K, Mwanyika-Sando M, et al. Disrespect and abuse during childbirth in Tanzania: are women living with HIV more vulnerable? J Acquir Immune Defic Syndr. 2014;67(Suppl 4): S228-34. https://doi.org/10.1097/QAl.0000000000000378.

32. Dwamena F, Holmes-Rovner M, Gaulden CM, Jorgenson S, Sadigh G, Sikorskii A, et al. Interventions for providers to promote a patient-centred approach in clinical consultations. Cochrane Database Syst Rev. 2012;12: CD003267. https://doi.org/10.1002/14651858.CD003267.pub2.

33. Sen G, Reddy B, lyer A. Beyond measurement: the drivers of disrespect and abuse in obstetric care. Reprod Health Matters. 2018;26:6-18. https://doi. org/10.1080/09688080.2018.1508173.

34. Long Q, Madede T, Parkkali S, Chavane L, Sundby J, Hemminki E. Maternity care system in Maputo, Mozambique: plans and practice? Cogent Med. 2017;4. https://doi.org/10.1080/2331205X.2017.1412138.

35. Hameed W, Avan BI. Women's experiences of mistreatment during childbirth: A comparative view of home- and facility-based births in Pakistan 2018. doi:https://doi.org/10.1371/journal.pone.0194601.

36. Larson E, Hermosilla S, Kimweri A, Mbaruku GM, Kruk ME. Determinants of perceived quality of obstetric care in rural Tanzania: a cross-sectional study. BMC Health Serv Res. 2014;14:483. https://doi.org/10.1186/1472-6963-14-483.

37. Banks KP, Karim AM, Ratcliffe HL, Betemariam W, Langer A. Jeopardizing quality at the frontline of healthcare: prevalence and risk factors for disrespect and abuse during facility-based childbirth in Ethiopia. Health Policy Plan. 2018;33:317-27. https://doi.org/10.1093/heapol/czx180.

38. Solnes Miltenburg A, van Pelt S, Meguid T, Sundby J. Disrespect and abuse in maternity care: individual consequences of structural violence. Reprod Health Matters. 2018;26:88-106.

39. Perera D, Lund R, Swahnberg K, Schei B, Infanti JJ, Darj E, et al. 'When helpers hurt': women's and midwives' stories of obstetric violence in state health institutions, Colombo district, Sri Lanka. BMC Pregnancy Childbirth. 2018;18:211. https://doi.org/10.1186/s12884-018-1869-z.

40. Standards for improving quality of maternal and newborn care in health facilities | RHL. https://extranet.who.int/rhl/guidelines/standards-improvingquality-maternal-and-newborn-care-health-facilities. Accessed 15 Feb 2017.

41. Bohren MA, Berger BO, Munthe-Kaas H, Tunçalp Ö. Perceptions and experiences of labour companionship: a qualitative evidence synthesis. Cochrane Database of Syst Rev. 2019;(3):CD012449. https://doi.org/10.1002/ 14651858.CD012449.pub2.

42. Category of Disrespect and Abuse i Corresponding Right. https://www. whiteribbonalliance.org/wp-content/uploads/2017/11//Final_RMC_Charter. pdf. Accessed 6 Nov 2018.

43. Miller $\mathrm{S}$, Abalos $E_{1}$ Chamillard M, Ciapponi A, Colaci D, Comandé $D$, et al. Beyond too little, too late and too much, too soon: a pathway towards evidence-based, respectful maternity care worldwide. Lancet. 2016;388: 2176-92. https://doi.org/10.1016/S0140-6736(16)31472-6.

44. Mukamurigo J, Dencker A, Ntaganira J, Berg M. The meaning of a poor childbirth experience - a qualitative phenomenological study with women in Rwanda. PLoS One. 2017;12:e0189371. https://doi.org/10.1371/journal.pone.0189371.

45. Påfs J, Rulisa S, Musafili A, Essén B, Binder-Finnema P. 'You try to play a role in her pregnancy' - a qualitative study on recent fathers' perspectives about 
childbearing and encounter with the maternal health system in Kigali, Rwanda. Glob Health Act. 2016;9:31482. https://doi.org/10.3402/gha.v9. 31482

46. McMahon SA, George AS, Chebet JJ, Mosha IH, Mpembeni RN, Winch PJ. Experiences of and responses to disrespectful maternity care and abuse during childbirth; a qualitative study with women and men in Morogoro region, Tanzania BMC Pregnancy Childbirth 2014;14:268. doi:https://doi.org/ 10.1186/1471-2393-14-268.

47. Kululanga LI, Sundby J, Malata A, Chirwa E. Striving to promote male involvement in maternal health care in rural and urban settings in Malawi a qualitative study; 2011.

48. Kululanga LI, Malata A, Chirwa E, Sundby J. Malawian fathers' views and experiences of attending the birth of their children: a qualitative study. BMC Pregnancy Childbirth. 2012;12:141. https://doi.org/10.1186/1471-2393-12-141.

49. FP High Impact Practices. 2017. https://www.fphighimpactpractices.org/ briefs/immediate-postpartum-family. Accessed 15 Oct 2018.

50. Lopez L, Grey T, Janet H, Chen M. Education for contraceptive use by women after childbirth. Cochrane Database Syst Rev. 2015;17:39-41.

51. Rossier C, Bradley SEK, Ross J, Winfrey W. Reassessing unmet need for family Planning in the postpartum period. Stud Fam Plan. 2015;46:355-67. https://doi.org/10.1111/j.1728-4465.2015.00037.x.

52. Duysburgh E, Kerstens B, Kouanda S, Kaboré CP, Belemsaga Yugbare D, Gichangi P, et al. Opportunities to improve postpartum care for mothers and infants: design of context-specific packages of postpartum interventions in rural districts in four sub-Saharan African countries. BMC Pregnancy Childbirth. 2015;15:131. https://doi.org/10.1186/s12884-015-0562-8.

53. Rajan S, Speizer IS, Calhoun LM, Nanda P. Counseling during maternal and infant health visits and postpartum contraceptive use in Uttar Pradesh, India. Int Perspect Sex Reprod Health. 2016;42:167. https://doi.org/10.1363/ 42e2816.

54. Tawfik Y, Rahimzai M, Ahmadzai M, Clark PA, Kamgang E. Integrating family planning into postpartum care through modern quality improvement: experience from Afghanistan. Glob Heal Sci Pract. 2014;2: 226-33. https://doi.org/10.9745/GHSP-D-13-00166.

55. Saeed GA, Fakhar S, Rahim F, Tabassum S. Change in trend of contraceptive uptake - effect of educational leaflets and counseling. Contraception. 2008;77:377-81. https:/doi.org/10.1016/J.CONTRACEPTION.2008.01.011

56. What is the proven high-impact practice in family planning service delivery? http://www.fphighimpactpractices.org/overview. Accessed 11 Oct 2018.

57. Family Planning 2020. http://www.familyplanning2020.org/resources/16437.

58. Family planning 2020 Country Action: Opportunities, challenges, and priorities. http://ec2-54-210-230-186.compute-1.amazonaws.com/wpcontent/uploads/2016/11/Country_Action_Opportunities-Challenges-andPriorities_MOZAMBIQUE_FINAL.pdf.

59. MISAU. Estratégia De Planeamento Familiar E; 2010. p. 2015

60. Familiar P, Servi O, Sanit U. Direcção Nacional De Saúde Pública Directrizes para Operacionalização da Integração do Planeamento Familiar em Outros Serviços na Unidade Sanitária Ficha Técnica:

61. Shakibazadeh E, Namadian M, Bohren MA, Vogel JP, Rashidian A, Nogueira Pileggi $V$, et al. Respectful care during childbirth in health facilities globally: a qualitative evidence synthesis. BJOG: An International Journal of Obstetrics and Gynaecology. 2018;125:932-42.

62. MW, Worku A, Medhanyie AA, Berhane Y. Mothers' experience of disrespect and abuse during maternity care in northern Ethiopia. Global Health Action. 2018;11(3):1465215.

\section{Publisher's Note}

Springer Nature remains neutral with regard to jurisdictional claims in published maps and institutional affiliations.

Ready to submit your research? Choose BMC and benefit from:

- fast, convenient online submission

- thorough peer review by experienced researchers in your field

- rapid publication on acceptance

- support for research data, including large and complex data types

- gold Open Access which fosters wider collaboration and increased citations

- maximum visibility for your research: over $100 \mathrm{M}$ website views per year

At BMC, research is always in progress.

Learn more biomedcentral.com/submissions 